\title{
Influence of substrate type and properties on root electrical capacitance**
}

\author{
Imre Cseresnyés ${ }^{1 *}$, Eszter Vozáry ${ }^{2}$, Sándor Kabos ${ }^{3}$, and Kálmán Rajkai ${ }^{1}$ \\ ${ }^{1}$ Department of Soil Physics and Water Management, Institute for Soil Sciences and Agricultural Chemistry, \\ Centre for Agricultural Research, Hungarian Academy of Sciences, H-1022 Budapest, Herman Ottó út 15, Hungary \\ ${ }^{2}$ Department of Physics and Control, Szent István University, H-1118 Budapest, Somlói út 14-16, Hungary \\ ${ }^{3}$ Department of Statistics, Eötvös Loránd University, H-1117 Budapest, Pázmány Péter stny. 1/A, Hungary
}

Received May 2, 2019; accepted September 5, 2019

\begin{abstract}
Three pot experiments were performed on cucumber, maize, soybean and wheat plants to investigate the effects of various substrate types, namely pumice, arenosol and chernozem soil (Exp. 1), of substrate salinity (Exp. 2) and of soil water content (SWC; Exp. 3) on the electrical capacitance measured in root-soil systems. The data were evaluated according to the basic principle of the two-dielectric capacitor model. Statistical analysis indicated that the capacitance measured in root-soil systems was determined by the capacitance of the root system for each combination of plant species and substrate. Furthermore, the results showed that substrate impedance had a negligible influence on the capacitance measured in root-soil systems. Substrate salinity had no direct effect on capacitance measured in root-soil systems, but salt-induced physicochemical changes in plant tissues could have influenced its dielectric properties. Capacitance measured in rootsoil systems increased exponentially with soil water content (it ranged from 10 to $48 \mathrm{v} / \mathrm{v} \%$ ), indicating that the measured capacitance was more sensitive to variability in moisture content at high rather than at low water saturation levels. This is not consistent with the general consensus that the capacitance method is unreliable in dry soil and should be used at soil water content close to field capacity. The present results will contribute to the more effective application of the root capacitance technique.

Keyw ord s: root electrical capacitance, root-soil system, soil salinity, soil water content, two-dielectric capacitor model
\end{abstract}

\section{INTRODUCTION}

The measurement of electrical capacitance in root-soil systems $\left(\mathrm{C}_{\mathrm{RSS}}\right)$ is a promising non-destructive approach in the estimation of root size and activity. The method is based on experimentally established correlations between $C_{R S S}$

*Corresponding author e-mail: cseresnyes.imre@agrar.mta.hu

**This work was financed by NKFIH (K-115714), GINOP-2.3.215-2016-00028 and a János Bolyai Research Scholarship from the Hungarian Academy of Sciences (2018-2021). and the mass, length or surface area of the whole root system (Chloupek, 1972; Cseresnyés et al., 2017). Capacitance is conventionally detected using an LCR meter at $\sim 1 \mathrm{kHz}$ current frequency between a ground electrode inserted into the substrate and a plant electrode (clamp or needle) fixed on the stem base (Aulen and Shipley, 2012; Postic and Doussan, 2016). This in-situ technique is suitable for monitoring ontogenetic changes in the root traits of the same plant cultivar. Since fine, absorbing roots make a substantially higher contribution to the $\mathrm{C}_{\mathrm{RSS}}$ value than suberized coarse roots, the capacitance response offers an insight into root system activity (Dalton, 1995).

The $C_{R S S}$ value recorded is very sensitive to the electrode protocol and substrate properties, so the data are only comparable when the same species is cultivated in the same soil (substrate) type with the same soil water content (SWC) (Chloupek et al., 2010; Aulen and Shipley, 2012). An increase in the distance of the plant electrode from the substrate surface leads to a hyperbolic decrease in $\mathrm{C}_{\mathrm{RSS}}$, pointing to the need for consistent electrode placement on the stem (Dalton, 1995; Ellis et al., 2013). The capacitance obtained was shown to be influenced by the size and shape of the ground electrode (Kormanek et al., 2016). Furthermore, SWC was previously reported to have a marked effect on $\mathrm{C}_{\mathrm{RSS}}$ (Chloupek, 1977; Dietrich et al., 2013). On the basis of an experiment with a single tomato plant, Dalton (1995) suggested that root capacitance should be consistently detected at a SWC corresponding to field capacity, this became the general consensus for measurement procedures for many years (Beem et al., 1998; Postic and Doussan, 2016).

(C) 2020 Institute of Agrophysics, Polish Academy of Sciences 
The first electrical model (Dalton, 1995) considered the root system to be cylindrical capacitors connected in parallel. The root membranes act as an imperfect dielectric in the capacitor, separating the two low-resistance conduits, i.e. the plant's internal medium and the soil solution. The polarizable root-soil interface stores electrical charges, exhibiting a capacitance proportional to the surface area. Dalton's model contains simplifications, e.g. wet soil is assumed to be purely conductive (with ohmic resistance only), although Chloupek (1977) formerly defined the capacitive character of loam soil and quartz sand. Therefore, Rajkai et al. (2005) recommended a two-dielectric capacitor model (TCM) consisting of series-connected root and soil dielectrics. According to the physical laws for capacitors connected in series (i.e. the reciprocal of the effective capacitance is the sum of the reciprocal of individual capacitances), if the soil capacitance $\left(\mathrm{C}_{\text {Soil }}\right)$ is much higher than the root capacitance $\left(\mathrm{C}_{\text {Root }}\right), \mathrm{C}_{\mathrm{RSS}}$ is determined by the root system (Rajkai et al., 2005; Dietrich et al., 2013). A subsequent study provided experimental support for the concept of TCM (Kormanek et al., 2016), and the high capacitances detected for various types of substrates at field capacity also meet the model's criteria (Dietrich et al., 2013; Ellis et al., 2013; Cseresnyés et al., 2017).

Assuming the validity of TCM, the purpose of the first pot experiment (Exp. 1) was to evaluate the extent to which the measured $C_{R S S}$ value represents $C_{\text {Root }}$ for different combinations of plant species and substrates. Although the soil ion content was considered by several authors (Chloupek, 1977; Ozier-Lafontaine and Bajazet, 2005) to be an influential factor in determining $\mathrm{C}_{\mathrm{RSS}}$, its effect on the capacitance response has not yet been tested. In Exp. 2 it was hypothesized that if the electrical capacitance and conductance of the substrate were much higher than those of the root system, then increasing substrate salinity would have no considerable effect on $\mathrm{C}_{\mathrm{RSS}}$, specifically on the parameters of regression between $\mathrm{C}_{\mathrm{RSS}}$ and root dry mass (RDM). The objective of Exp. 3 was to statistically evaluate the relationships between $\mathrm{C}_{\mathrm{RSS}}$ and $\mathrm{SWC}$, and to compare the magnitude of $\mathrm{C}_{\mathrm{RSS}}$ and $\mathrm{C}_{\text {Soil }}$ under a wide range of soil moisture conditions. These results may be important for the field application of the capacitance technique. Overall, the aim was to provide practical recommendations for using the $\mathrm{C}_{\mathrm{RSS}}$ method under various substrate conditions, thereby contributing to the enhanced reliability of the measurements.

\section{MATERIALS AND METHODS}

Exp. 1, which was focused on the study of the influence of substrate type, was randomized in complete blocks with four plant species, cucumber (Cucumis sativus L. $c v$. Perez), maize (Zea mays L. cv. DC488), soybean (Glycine $\max$ L. Merr. cv. Martina) and spring wheat (Triticum aestivum L. cv. TC33), and three substrates, pumice, arenosol and chernozem soil (Table 1), with 30 replicates. The germinated seeds were planted, one per $3.75 \mathrm{dm}^{3}(16 \mathrm{~cm}$ height and $18 \mathrm{~cm}$ upper diameter) plastic pot filled with dried, coarsely sieved media. The plants were cultivated in a growth room at $28 / 18^{\circ} \mathrm{C}$ with a $16 \mathrm{~h}$ photoperiod and PAR of $500 \mu \mathrm{mol} \mathrm{m} \mathrm{m}^{-2} \mathrm{~s}^{-1}$. All pots were watered daily to field capacity (17.9-35.9 v/v\%) on a balance $( \pm 1 \mathrm{~g})$. SWC was checked with a IMKO-HD2 portable TDR meter attached to a Pico32 probe with $110 \mathrm{~mm}$ rod length (IMKO GmbH, Ettlingen, Germany). The pumice was fertilized weekly with $100 \mathrm{~cm}^{3}$ of Hoagland's solution.

After watering the plants to field capacity, the pots were transported to the laboratory to adjust the temperature, $23 \pm 0.5^{\circ} \mathrm{C}$. Then $C_{R S S}$ values with a dissipation factor $\left(D_{R S S}\right.$; the ratio of dielectric losses to energy storage) were measured using a GW-8101G LCR meter (GW Instek Co. Ltd., Taiwan) set to a parallel equivalent circuit at $1 \mathrm{kHz}$ and $1 \mathrm{~V} \mathrm{AC}$. The ground electrode was a stainless steel rod, $18 \mathrm{~cm}$ long and $0.6 \mathrm{~cm}$ i.d. (303S31; RS Pro $\mathrm{GmbH}$, Gmünd, Austria) inserted into the substrate to a $15 \mathrm{~cm}$ depth $8 \mathrm{~cm}$ from the stem (avoiding direct contact with the pot). The plant electrode was clamped precisely $10 \mathrm{~mm}$ above the

Table 1. Characterization of the substrates used for the pot experiments

\begin{tabular}{|c|c|c|c|}
\hline Substrate properties & Pumice & Arenosol & Chernozem \\
\hline Sand/silt/clay content (\%) & - & $80.9 / 11.9 / 7.2$ & $20.1 / 56.5 / 23.4$ \\
\hline Bulk density $\left(\mathrm{g} \mathrm{cm}^{-3}\right)$ & 0.92 & 1.55 & 1.37 \\
\hline Field capacity (v/v\%) & 17.9 & 19.0 & 35.9 \\
\hline $\mathrm{pH}\left(\mathrm{H}_{2} \mathrm{O}\right)$ & 6.53 & 7.52 & 7.86 \\
\hline $\mathrm{CEC}\left(\mathrm{mmol} 100 \mathrm{~g}^{-1}\right)$ & 2.20 & 8.39 & 11.71 \\
\hline Lime content (\%) & 0 & 0.29 & 4.09 \\
\hline Humus content (\%) & 0 & 1.18 & 4.18 \\
\hline $\mathrm{N}($ total $) / \mathrm{P} / \mathrm{K}$ content $\left(\mathrm{mg} \mathrm{kg}^{-1}\right)$ & $70 / 0 / 179$ & $730 / 438 / 222$ & $1830 / 167 / 345$ \\
\hline Origin & 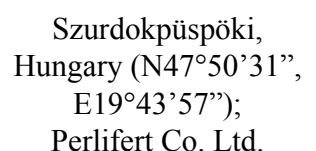 & $\begin{array}{c}\text { Örbottyán, Hungary } \\
\text { (N4740’38”, E19¹4'50") }\end{array}$ & $\begin{array}{c}\text { Martonvásár, Hungary } \\
\left.\text { (N47¹8’42", E18 } 46^{\circ} 37^{\prime \prime}\right)\end{array}$ \\
\hline
\end{tabular}


substrate surface through a 5-mm-wide aluminium strip wrapped around the stem. Conductivity gel was smeared under the strip. Before measuring the root-substrate system, the dielectric responses of the substrates $\left(\mathrm{C}_{\text {Soil }}\right.$ and $\left.\mathrm{D}_{\text {Soil }}\right)$ were detected in all pots between two identical ground electrodes inserted $8 \mathrm{~cm}$ apart. One plant from each block was subjected to measurement daily over a 30 -day period (plant age: 6-35 days) in order to obtain a wide RDM range for data evaluation. Directly after the measurements, the stems were cut at the substrate surface. The roots were carefully washed free of substrate over a $0.2-\mathrm{mm}$ sieve followed by root flotation, after which they were oven-dried $\left(70^{\circ} \mathrm{C}\right)$ to a constant weight in order to determine $\operatorname{RDM}( \pm 0.001 \mathrm{~g})$.

The $\mathrm{C}_{\text {Root }}$ values were calculated according to Eq. (12) (see Appendix), based on the TCM principle. Linear regression was used to relate $\mathrm{C}_{\mathrm{RSS}}$ or $\mathrm{C}_{\text {Root }}$ to RDM. The $F$-test was performed to compare the $\mathrm{C}_{\mathrm{RSS}}-\mathrm{RDM}$ and $\mathrm{C}_{\mathrm{Root}}-\mathrm{RDM}$ relationships for each plant-substrate system, assuming the equality in slope and $y$-intercept of the two regressions. The statistical significance was assessed at $p<0.05$ in each case.

Exp. 2 was performed to investigate salinity-alkalinity stress, it was carried out using spring wheat (composite cross population) seedlings planted in $1.25 \mathrm{dm}^{3}(13 \mathrm{~cm}$ height and $11.5 \mathrm{~cm}$ upper diameter) plastic pots. Pumice was chosen as the rooting media due to its low cation exchange

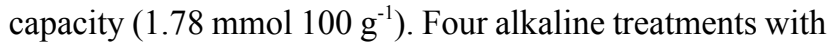
24 replicates were applied, including a control $(\mathrm{CON})$, as well as $0.5 \mathrm{~g}(\mathrm{~S} 1), 1 \mathrm{~g}(\mathrm{~S} 2)$ and $2 \mathrm{~g}(\mathrm{~S} 3) \mathrm{Na}_{2} \mathrm{CO}_{3} \mathrm{~kg}^{-1}$ substrate concentrations, with a substrate $\mathrm{pH}$ of $6.44,7.76$, 8.63 and 9.35, respectively. Each pot was irrigated before planting with $200 \mathrm{~cm}^{3}$ of distilled water $(\mathrm{CON})$ or aqueous $\mathrm{Na}_{2} \mathrm{CO}_{3}$ solution (S1-S3). The growth conditions, plant irrigation and nutrition were similar to those in Exp. 1.

All of the plants were grown until the 42nd day, when $\mathrm{C}_{\mathrm{RSS}}$ and $\mathrm{C}_{\mathrm{Soil}}$ were recorded in each pot. The measurement procedure was the same as in Exp. 1, except for the $10-\mathrm{cm}$ insertion depth and $4 \mathrm{~cm}$ distance (from the stem) of the ground electrode due to the small size of the pot. The plants were then harvested to determine RDM. The effect of salinity on $\mathrm{C}_{\text {Soil }}$ was evaluated using the unpaired $t$ test. $\mathrm{C}_{\mathrm{RSS}}-\mathrm{RDM}$ linear regressions were established for each treatment, after which the F-test was applied to assess the quality of the model parameters.

The aim of Exp. 3 was to study the effect of SWC, spring wheat (cv. TC33) seedlings were planted in $1.25 \mathrm{dm}^{3}$ (13 $\mathrm{cm}$ height and $11.5 \mathrm{~cm}$ upper diameter) pots. Chernozem soil (different from that used in Exp.1) was used to simulate field conditions in response to SWC. The soil was watered to field capacity. A total of 12 replicates were obtained by planting one seedling at a time three times a week for four weeks to ensure a wide range of RDM values at the terminal harvest. The plants were grown as described in Exp. 1. Two days after the last planting, watering was suspended to reduce SWC to near wilting point $(9.7 \mathrm{v} / \mathrm{v} \%)$ in all pots. SWC was checked regularly with a TDR meter. When the wilting point was approached (plant age: $12-28$ days), the SWC around the roots was precisely detected, after which $\mathrm{C}_{\mathrm{RSS}}$ and $\mathrm{C}_{\text {Soil }}$ were recorded in each pot (see Exp. 1). Thereafter, the pot drain holes were closed, and $50 \mathrm{~cm}^{3}$ of distilled water was poured over the soil. An hour later, soil moisture and capacitance were measured again (the electrodes were left in place throughout the experiment). The irrigation and measurement steps were repeated (ten times altogether) until the soil became fully water-saturated (47.6 $\mathrm{v} / \mathrm{v} \%$ ). Finally, RDM was determined after the harvest.

All of the SWC values were converted to relative water saturation $\left(\theta_{\mathrm{rel}}\right)$. $\mathrm{AC}_{\mathrm{RSs}}-\theta_{\mathrm{rel}}$ function $(\mathrm{n}=10)$ was established for each of the 12 plants; $R^{2}$ was calculated using the linearized $\ln \left(\mathrm{C}_{\mathrm{RSS}}\right)=\ln (\mathrm{a})+\mathrm{b} \theta_{\text {rel }}$ formula (Quinn and Keough, 2002). For a given specimen, all $C_{R S S}$ data were divided by the capacitance value detected in water-saturated soil $\left(\theta_{\text {rel }}=1\right)$ to obtain the relative capacitance, $\mathrm{C}_{\mathrm{rel}}$. A linearized $\mathrm{C}_{\mathrm{rel}}-\theta_{\text {rel }}$ model was applied, and the $\mathrm{F}$ statistic was used to test the hypothesis of equal model parameters. As the $y$-intercepts proved to be significantly different, Spearman's rank correlation analysis was conducted to measure the strength of monotonic association between the y-intercept and the plant age (day) or RDM.

\section{RESULTS}

In Exp. 1, $\mathrm{C}_{\text {Soil }}$ was found to be $6.93 \pm 0.06 \mathrm{nF}$ (mean \pm SE; $\mathrm{n}=120), 29.7 \pm 0.18 \mathrm{nF}$ and $17.9 \pm 0.10 \mathrm{nF}$ for pumice, arenosol and chernozem soil, respectively, with corresponding $D_{\text {Soil }}$ values of $30.2 \pm 0.12,23.1 \pm 0.13$ and $15.5 \pm 0.15$. The $\mathrm{C}_{\mathrm{RSS}}$ values detected ranged from 0.363 to $14.9 \mathrm{nF}$, depending on the species, plant age and substrate type. $D_{\text {RSS }}$ was between $2.45 \pm 0.12($ mean \pm SE; $n=30)$ and $3.92 \pm 0.12$ for the various plant-substrate systems. Different plants exhibited $0.009-1.974 \mathrm{~g}$ RDM. All of the $\mathrm{C}_{\mathrm{RSS}}-\mathrm{RDM}$ regressions proved to be highly significant $(\mathrm{p}<0.001 ; \mathrm{n}=30)$ with $\mathrm{R}^{2}$ ranging from 0.592 to 0.942 , and with large differences in slopes (0.573-11.1 $\mathrm{nF} \mathrm{g}^{-1}$ RDM; Fig. 1). The regressions between the calculated $\mathrm{C}_{\text {Root }}$ and RDM showed very similar $\mathrm{R}^{2}$ values (0.607-0.654) and 5.7-14.6\% steeper slopes (0.612-12.5 $\left.\mathrm{nF} \mathrm{g}^{-1} \mathrm{RDM}\right)$ compared to the corresponding $\mathrm{C}_{\mathrm{RSS}}-\mathrm{RDM}$ relationships. The F-test revealed no significant difference in slope and $y$-intercept between the $\mathrm{C}_{\mathrm{RSS}}-\mathrm{RDM}$ and $\mathrm{C}_{\mathrm{Root}} \mathrm{RDM}$ regressions for any plant-substrate system $\left(\mathrm{F}_{2.56}: 0.318-1.93 ; \mathrm{p}: 0.154-0.729\right)$.

In Exp. 2, $\mathrm{C}_{\text {Soil }}$ increased with salinity, with values of $6.70 \pm 0.16 \mathrm{nF}($ mean $\pm \mathrm{SE} ; \mathrm{n}=24), 7.01 \pm 0.18 \mathrm{nF}, 7.18 \pm 0.20$ $\mathrm{nF}$ and $7.43 \pm 0.18 \mathrm{nF}$ for the CON, S1, S2 and S3 treatments, respectively. However, the difference only proved to be significant between the $\mathrm{CON}$ and $\mathrm{S} 3$ plants $(\mathrm{t}=2.97$; $\mathrm{p}<0.01)$. Increasing alkalinity resulted in a consistent reduction in $\mathrm{C}_{\mathrm{RSS}}$ with values of $5.68 \pm 0.11 \mathrm{nF}$ (mean $\pm \mathrm{SE}$; $\mathrm{n}=24), 5.21 \pm 0.12 \mathrm{nF}, 3.66 \pm 0.08 \mathrm{nF}$ and $2.75 \pm 0.07 \mathrm{nF}$ for the CON, S1, S2 and S3 plant groups, respectively. The harvested plants had RDM values of $0.691 \pm 0.012 \mathrm{~g}, 0.589$ 

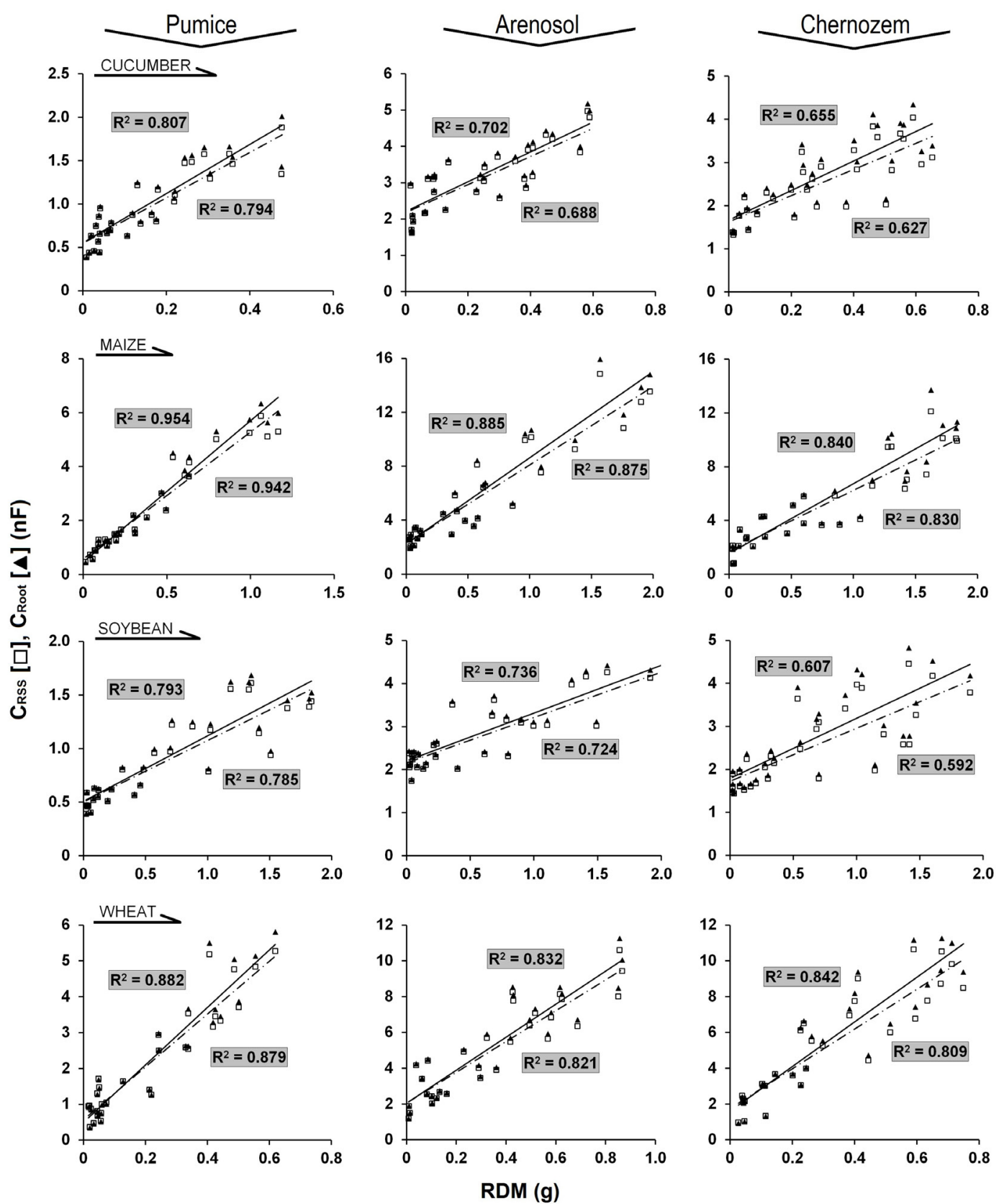

Fig. 1. Relationship between the electrical capacitance of the root-substrate systems $\left(\mathrm{C}_{\mathrm{RSS}}\right.$ in nanofarads, $\mathrm{nF}$; $\square$ and dashed line $)$ or the calculated electrical capacitance of the roots $\left(\mathrm{C}_{\mathrm{Root}} ; \boldsymbol{\Delta}\right.$ and solid line) and the root dry mass (RDM; $\left.\mathrm{g}\right)$ for various species and substrate types.

$\pm 0.012 \mathrm{~g}, 0.405 \pm 0.008 \mathrm{~g}$ and $0.297 \pm 0.007 \mathrm{~g}$ in the same treatments. A close linear correlation was found between $\mathrm{C}_{\mathrm{RSS}}$ and $\mathrm{RDM}\left(\mathrm{R}^{2}: 0.579-0.663 ; \mathrm{p}<0.001 ; \mathrm{n}=24\right)$ at each salinity level (Fig. 2). Hypothesizing the equality of both slopes and y-intercepts, the difference was significant across the four lines $\left(\mathrm{F}_{6.88}=2.33 ; \mathrm{p}=0.039\right)$, but was insignificant across the S1, S2 and S3 regressions $\left(\mathrm{F}_{4.88}=0.253\right.$; $\mathrm{p}=0.907)$. As no significant difference was found between the four regressions when the equality of slopes was tested
$\left(F_{3.88}=0.015 ; p=0.998\right)$, the aforementioned significance was clearly due to differences in the $y$-intercept between the $\mathrm{CON}$ and $\mathrm{S} 1-\mathrm{S} 2-\mathrm{S} 3$ groups.

In Exp. 3, wheat plants of different ages exhibited $C_{R S S}$ values ranging from 1.88 to $7.79 \mathrm{nF}$ in water-saturated soil, with RDM ranging from 0.030 to $0.635 \mathrm{~g}$. A strong correlation $(\mathrm{p}<0.001 ; \mathrm{n}=10)$ between $\mathrm{C}_{\mathrm{RSS}}$ and $\theta_{\text {rel }}$ was observed for each specimen, with $\mathrm{R}^{2}$ ranging from 0.870 to 0.955 when applied to the linearized form (Fig. 3a). As regards the $\mathrm{C}_{\text {rel }}-\theta_{\text {rel }}$ functions (Fig. $3 b$ ), the $y$-intercept 


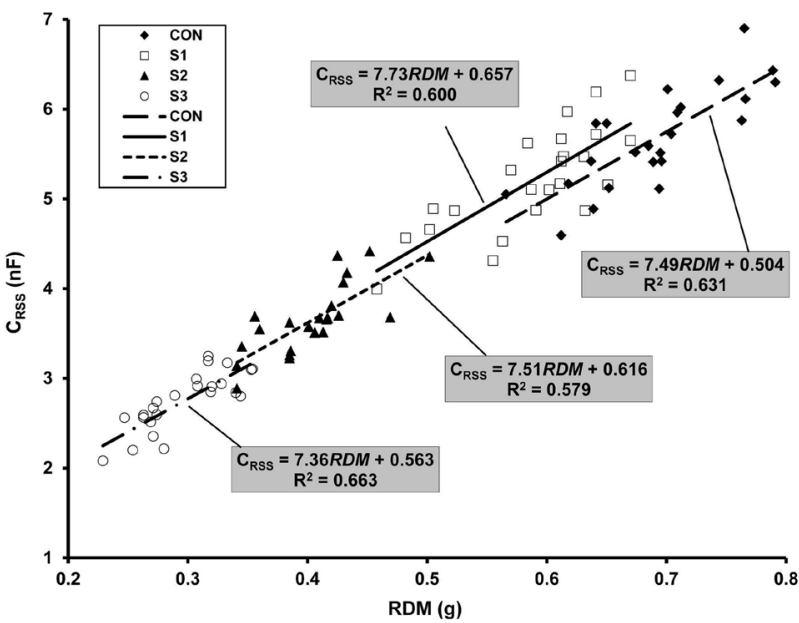

Fig. 2. Relationship between the electrical capacitance of the root-substrate systems $\left(\mathrm{C}_{\mathrm{RSS}}\right.$ in nanofarads, $\left.\mathrm{nF}\right)$ and root dry mass (RDM; g) for wheat plants exposed to various levels of alkalinity. CON: control; S1, S2 and S3: 0.5, 1 and $2 \mathrm{~g} \mathrm{Na}_{2} \mathrm{CO}_{3} \mathrm{~kg}^{-1}$ pumice substrate, respectively.

and slope were within the ranges of 0.141-0.214 and 1.511.98 , respectively. The $\mathrm{C}_{\mathrm{rel}}-\theta_{\text {rel }}$ functions were significantly different $\left(\mathrm{F}_{22.96}=1.72 ; \mathrm{p}=0.039\right)$, but proved to be statistically equivalent in terms of their slopes $\left(\mathrm{F}_{11.96}=0.823\right.$; $\mathrm{p}=0.617)$. Although the parameter estimation was made after linearization (logarithmic scale), the $\mathrm{R}^{2}$ values were calculated using the original (exponential) scale. According to Spearman's rank correlation analysis, the y-intercept was significantly negatively correlated with plant age $(\mathrm{S}=$ $474 ; \mathrm{r}=-0.657 ; \mathrm{p}=0.024)$, and only weakly correlated with RDM $(\mathrm{S}=450 ; \mathrm{r}=-0.573 ; \mathrm{p}=0.055)$. At any $\mathrm{SWC}$, $\mathrm{C}_{\text {Soil }}$ was at least an order of magnitude higher than $\mathrm{C}_{\mathrm{RSS}}$ (Fig. 3c), and showed a strong positive linear correlation with $\theta_{\text {rel }}\left(\mathrm{R}^{2}=0.938 ; \mathrm{p}<0.001 ; \mathrm{n}=120\right)$.

\section{DISCUSSION}

The close relationships between $\mathrm{C}_{\mathrm{RSS}}$ and $\mathrm{RDM}$ (Exp. 1) demonstrate that the capacitance detected was a reliable predictor of root system size for various species and growing media. The large differences in the regression parameters were consistent with previous observations (Beem et al., 1998; Aulen and Shipley, 2012; Cseresnyés et al., 2017), and showed the relative nature of $\mathrm{C}_{\mathrm{RSS}}$ measurement. The regression fit $\left(\mathrm{R}^{2}\right)$ decreased with increasing substrate complexity (pumice $<$ arenosol $<$ chernozem) due to the dielectric behaviour of the variably charged soil colloids, including clay minerals and organic materials (Hilhorst, 1998), which cause interference with the plant response (Ozier-Lafontaine and Bajazet, 2005; Postic and Doussan, 2016). In each case, $C_{\text {Soil }}$ and $D_{\text {Soil }}$ were found to be considerably higher than $C_{R S S}$ and $D_{R S S}$, respectively. Therefore, the calculated $\mathrm{C}_{\mathrm{Root}}$ value was a good approximation of the measured $\mathrm{C}_{\mathrm{RSS}}$, as indicated by statistical equivalence of the parameters between the $\mathrm{C}_{\mathrm{RSS}} \mathrm{RDM}$ and the corresponding $\mathrm{C}_{\mathrm{Root}}-\mathrm{RDM}$ regressions obtained for each plant-substrate system. These results suggest that the plant-substrate impedance response is influenced jointly by resistance and
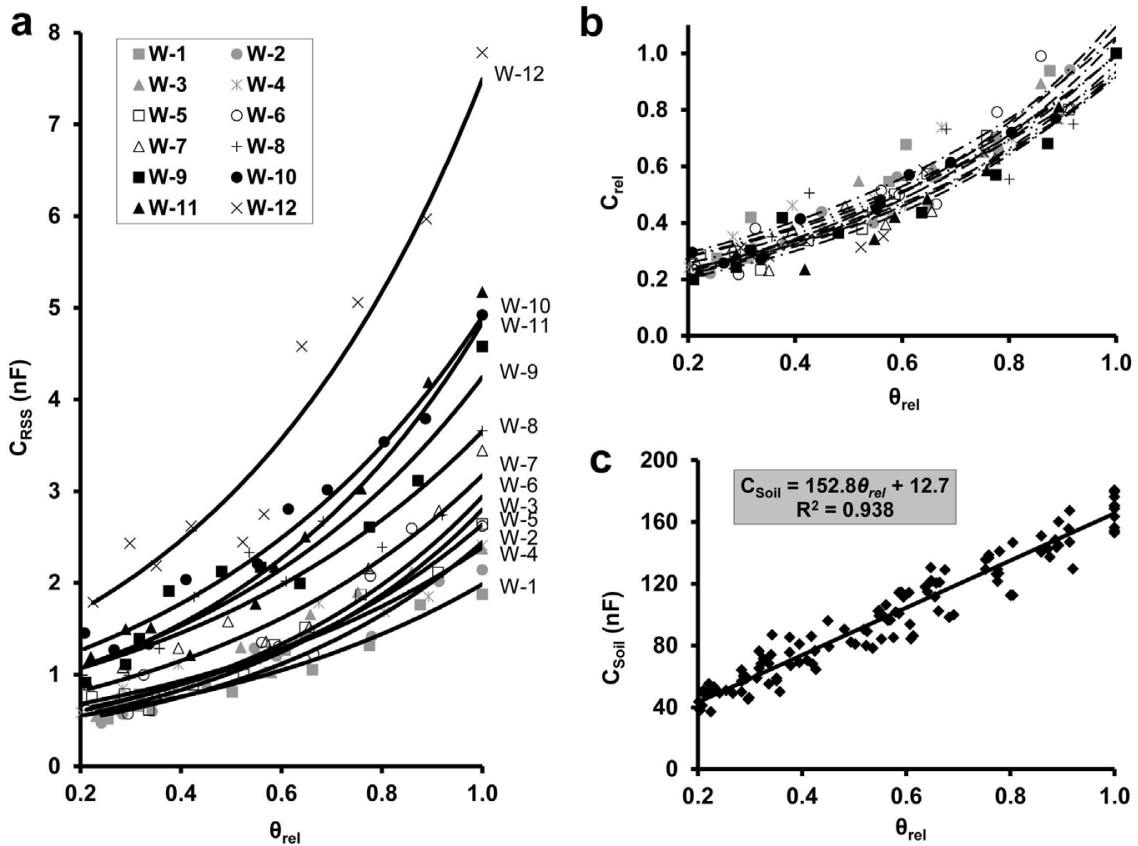

Fig. 3. Relationship between: a - the electrical capacitance of root-soil systems $\left(\mathrm{C}_{\mathrm{RSS}}\right.$ in nanofarads, $\left.\mathrm{nF}\right)$ and the relative water saturation $\left(\theta_{\text {rel }}\right)$ of chernozem soil. W-1...W-12 are wheat plants in order of increasing root dry mass; $b$ - the relative root electrical capacitance $\left(\mathrm{C}_{\mathrm{rel}}\right)$ and $\theta_{\text {rel }} \cdot \mathrm{C}_{\mathrm{rel}}$ is the ratio of $\mathrm{C}_{\mathrm{RSS}}$ to capacitance detected for the given plant at $\theta_{\mathrm{rel}}=1 ; \mathrm{c}-$ the electrical capacitance of chernozem soil $\left(\mathrm{C}_{\mathrm{Soil}}\right)$ and $\theta_{\text {rel. }}$. 
capacitance (not only by resistance), and that substrate impedance has a negligible effect on plant response. These findings are in accordance with the basic assumptions of TCM, because - due to the high $\mathrm{C}_{\text {Soil }}$ values - the roots represented the main capacitance term for the plant-substrate system. Ellis et al. (2013) also found soil impedances to be principally resistive, thus having little influence over $C_{R S S}$ measurements.

Substrate alkalization (Exp. 2) had no effect on the slope of the empirical correlations between $\mathrm{C}_{\mathrm{RSS}}$ and $\mathrm{RDM}$, but, irrespective of the salinity level, it significantly increased the y-intercept compared to the control plants. As the high mean $\mathrm{C}_{\text {Soil }}$ increased further with salt concentration, and was only significant between the CON and S3 treatments, it was surmised that the above result was not due to altered soil electrical properties, but was attributable rather to salt-induced changes in the plant, including physicochemical alterations in root membranes and morpho-anatomical modifications in the root system and stem base (Bernstein, 2013; Cseresnyés et al., 2018a). According to the revised model suggested by Dietrich $\mathrm{et}$ al. (2013), a positive regression intercept may be attributed to the capacitance of plant stem tissues between the substrate surface and the plant electrode. The equal slopes of the four lines, the lack of a trend in the $y$-intercept with increasing alkalinity, and the weakly significant $(\mathrm{p}=0.039)$ difference between the control and salinized plants all suggest that substrate salinity has little influence on $\mathrm{C}_{\mathrm{RSS}}$.

Exp. 3 demonstrated that $\mathrm{C}_{\text {Soil }}$ increased with SWC. Since water has a much higher relative permittivity $\left(\varepsilon_{\mathrm{r}}\right.$ $\sim 80$ at $1 \mathrm{kHz})$ than solid soil constituents $\left(\varepsilon_{\mathrm{r}}<5\right)$ or air $\left(\varepsilon_{\mathrm{r}} \sim 1\right)$, the water dielectric response becomes dominant as the soil becomes wetter (Hilhorst, 1998). A similar relationship was observed for potting compost and loam soil (Dietrich et al., 2013). The exponential $\mathrm{C}_{\mathrm{rel}}-\theta_{\text {rel }}$ functions were statistically equal in terms of slope, but the $y$-intercept showed a negative correlation with plant age. This is presumably due to age-dependent histological changes in the roots and stem base, which influence the dielectric response by altering the proportion of apoplastic to symplastic current pathways (Cseresnyés et al., 2018a). This finding seems to be dependent on the plant species, as previous investigations concerning soybean and maize did not show such an effect (Cseresnyés et al., 2018b). Dalton (1995) and Dietrich et al. (2013) stated that a decrease in SWC caused a reduction in the root surface area in contact with soil pore water and thus a reduction in the measured capacitance. In contrast, Ellis et al. (2013) suggested that, as the root surface area is much larger than the electrode surface area, decreasing capacitance in a drying soil was more likely due to reduced electrode-soil contact. The exponential relationship between $\mathrm{C}_{\mathrm{RSS}}$ and $\theta_{\text {rel }}$ was inconsistent with the results of Dalton (1995), who found the SWC effect to be minimal at $\theta_{\text {rel }}$ from 0.35 to 0.85 and thus recommended this SWC range (primarily field capacity) for $\mathrm{C}_{\mathrm{RSS}}$ meas- urements. However, the results presented show that $C_{\text {RSS }}$ became increasingly sensitive to SWC as water saturation increased, suggesting that identical moisture conditions are even more important for the comparison of capacitance data at high water saturation levels. In accordance with this finding, a closer correlation was demonstrated between $\mathrm{C}_{\mathrm{RSS}}$ and canola root traits before rather than after substrate irrigation (Wu et al., 2017). A previous study also revealed that RDM could be reliably estimated by $\mathrm{C}_{\mathrm{RSS}}$ when SWC was close to the wilting point (Cseresnyés et al., 2018b). Although $\mathrm{C}_{\mathrm{RSS}}$ was found to be considerably lower than $\mathrm{C}_{\text {Soil }}$ at any SWC (i.e. the $\mathrm{C}_{\mathrm{RSS}}$ detected was determined by the root system in the case of series-connected root and soil dielectrics), this relationship should to be verified for the actual combination of plant species and rooting medium tested.

\section{CONCLUSIONS}

1. Taking into account the fundamental physical principle of TCM, the above experiments provided statistical evidence supporting the fact that $\mathrm{C}_{\mathrm{RSS}}$ was dominated by root capacitance, irrespective of the plant species and substrate type.

2. The results suggest that $C_{R S S}$ is not directly influenced by substrate salinity. However, further experiments with revised statistics will be necessary to draw more reliable conclusions.

3. The exponential increase in $\mathrm{C}_{\mathrm{RSS}}$ with SWC clearly shows that the accuracy of the capacitance method is more sensitive to variability in moisture content when the measurements are made at a high soil water level, i.e. at the conventionally recommended field capacity. Moreover, the results support the ability of the method to estimate root size efficiently in dry soil environments, which could be particularly relevant for field application.

Conflict of interest: The authors declare that they have no conflict of interest.

\section{REFERENCES}

Aulen M. and Shipley B., 2012. Non-destructive estimation of root mass using electrical capacitance on ten herbaceous species. Plant Soil, 355, 41-49.

https://doi.org/10.1007/s11104-011-1077-3

Beem J. van, Smith M.E., and Zobel R.W., 1998. Estimating root mass in maize using a portable capacitance meter. Agron. J., 90, 566-570.

https://doi.org/10.2134/agronj1998.00021962009000040021x

Bernstein N., 2013. Effects of salinity on root growth. In: Plant Roots: The Hidden Half (Eds A. Eshel, T. Beeckman). CRC Press, Boca Raton, FL, USA, 36/1-18. https://doi.org/10.1201/b14550-42

Chloupek O., 1972. The relationship between electric capacitance and some other parameters of plant roots. Biol. Plantarum, 14, 227-230. https://doi.org/10.1007/bf02921255 
Chloupek O., 1977. Evaluation of the size of a plant's root system using its electrical capacitance. Plant Soil, 48, 525-532. https://doi.org/10.1007/bf02187258

Chloupek O, Dostál V., Středa T., Psota V., and Dvořáčková O., 2010. Drought tolerance of barley varieties in relation to their root system size. Plant Breeding, 129, 630-636. https://doi.org/10.1111/j.1439-0523.2010.01801.x

Cseresnyés I., Kabos S., Takács T., Végh R.K., Vozáry E., and Rajkai K., 2017. An improved formula for evaluating electrical capacitance using the dissipation factor. Plant Soil, 419, 237-256. https://doi.org/10.1007/s11104-017-3336-4

Cseresnyés I., Rajkai K., Takács T., and Vozáry E., 2018a. Electrical impedance phase angle as an indicator of plant root stress. Biosyst. Eng., 169, 226-232.

https://doi.org/10.1016/j.biosystemseng.2018.03.004

Cseresnyés I., Szitár K., Rajkai K., Füzy A., Mikó P., Kovács R., and Takács T., 2018b. Application of electrical capacitance method for prediction of plant root mass and activity in field-grown crops. Front. Plant Sci., 9, 93. https://doi.org/10.3389/fpls.2018.00093

Dalton F.N., 1995. In-situ root extent measurements by electrical capacitance methods. Plant Soil, 173, 157-165. https://doi.org/10.1007/bf00155527

Dietrich R.C., Bengough A.G., Jones H.G. and White P.J., 2013. Can root electrical capacitance be used to predict root mass in soil? Ann. Bot., 112, 457-464. https://doi.org/10.1093/aob/mct044
Ellis T., Murray W., Paul K., Kavalieris L., Brophy J., Williams C., and Maass M., 2013. Electrical capacitance as a rapid non-invasive indicator of root length. Tree Physiol., 33, 3-17. https://doi.org/10.1093/treephys/tps115

Hilhorst M.A., 1998. Dielectric characterisation of soil. Ph.D. Thesis, Wageningen Agricultural University, The Netherlands.

Kormanek M., Gląb T., and Klimek-Kopyra A., 2016. Modification of the tree root electrical capacitance method under laboratory conditions. Tree Physiol., 36, 121-127. https://doi.org/10.1093/treephys/tpv088

Ozier-Lafontaine H. and Bajazet T., 2005. Analysis of root growth by impedance spectroscopy (EIS). Plant Soil, 277, 299-313. https://doi.org/10.1007/s11104-005-7531-3

Postic F. and Doussan C., 2016. Benchmarking electrical methods for rapid estimation of root biomass. Plant Methods, 12, 33. https://doi.org/10.1186/s13007-016-0133-7

Quinn G.P. and Keough M.J., 2002. Experimental design and data analysis for biologists. Cambridge University Press.

Rajkai K., Végh R.K., and Nacsa T., 2005. Electrical capacitance of roots in relation to plant electrodes, measuring frequency and root media. Acta Agron. Hung., 53, 197-210. doi:10.1556/AAgr.53.2005.2.8

Wu W., Duncan R.W., and Ma B-L., 2017. Quantification of canola root morphological traits under heat and drought stresses with electrical measurements. Plant Soil, 415, 229244. doi:10.1007/s11104-016-3155-z 


\section{Appendix}

According to our concept, the electrical impedance of the root-soil system $\left(Z_{R S S}\right)$ is the sum of the soil and the root impedance: $Z_{\mathrm{RSS}}=Z_{\text {Soil }}+Z_{\text {Root }}$. Both of these impedances can be represented by a parallel-connected resistor (R) and capacitor $(C)$ connected in parallel. In this model, $Z=R /(1+i \omega R C)$, where $i$ is the imaginary unit and $\omega=$ $2 \pi \mathrm{f}, \mathrm{f}$ is the $\mathrm{AC}$ frequency. The electrical impedance is a complex number, which is determined by the real part (ReZ) and the imaginary part (ImZ), as Z $=\operatorname{ReZ}+\mathrm{iImZ}$. Our precision LCR meter allows us to measure not only the real and imaginary part of impedance, but also the other two impedance parameters. If we consider our sample as a parallel $\mathrm{RC}$ circuit, we can measure the value of $\mathrm{C}$ directly and the dissipation factor, $\mathrm{D}$, which is the ratio of the real to the imaginary part of impedance. In this work, the parallel $\mathrm{C}$ value and $\mathrm{D}$ were chosen for measurement, because $\mathrm{C}$ is dependent on the root system size during plant development.

The two-dielectric capacitor model considers the root-soil system (RSS) as series-connected root and soil dielectrics, both of which are lossy capacitors (parallel RC circuits).
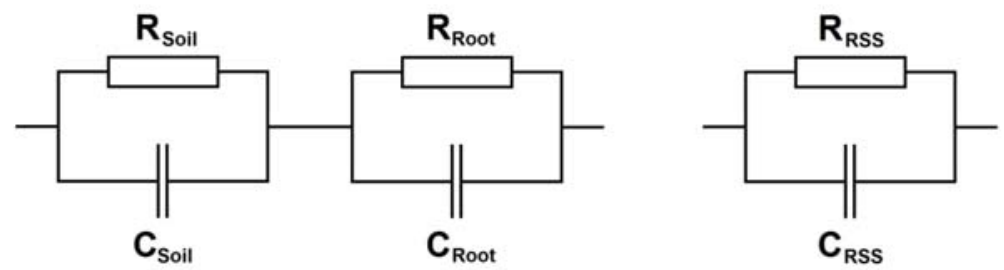

For a parallel $\mathrm{RC}$ circuit, $\mathrm{D}=1 /(\omega \mathrm{CR})$. The real (Eq. 1-3) and imaginary (Eq. 4-6) part of electrical impedance for RC circuits may be expressed using $\mathrm{D}$ and $\mathrm{C}$, as:

$$
\begin{array}{lll}
\frac{\mathrm{D}_{\text {Soil }}}{\omega \mathrm{C}_{\text {Soil }}\left(1+\mathrm{D}_{\text {Soil }}^{2}\right)}, & \frac{\mathrm{D}_{\text {Root }}}{\omega \mathrm{C}_{\text {Root }}\left(1+\mathrm{D}_{\text {Root }}^{2}\right)} & \frac{\mathrm{D}_{\text {RSS }}}{\omega \mathrm{C}_{\mathrm{RSS}}\left(1+\mathrm{D}_{\mathrm{RSS}}^{2}\right)} \\
\frac{1}{\omega \mathrm{C}_{\text {Soil }}\left(1+\mathrm{D}_{\text {Soil }}^{2}\right)} & \frac{1}{\omega \mathrm{C}_{\text {Root }}\left(1+\mathrm{D}_{\text {Root }}^{2}\right)} & \frac{1}{\omega \mathrm{C}_{\mathrm{RSS}}\left(1+\mathrm{D}_{\mathrm{RSS}}^{2}\right)}
\end{array}
$$

The sum of the real parts for the soil and root circuits is equal to the real part for the RSS circuit (Eq. 7), and this is also true for the imaginary parts (Eq. 8):

$$
\begin{aligned}
& \frac{\mathrm{D}_{\text {Soil }}}{\omega \mathrm{C}_{\text {Soil }}\left(1+\mathrm{D}_{\text {Soil }}^{2}\right)}+\frac{\mathrm{D}_{\text {Root }}}{\omega \mathrm{C}_{\text {Root }}\left(1+\mathrm{D}_{\text {Root }}^{2}\right)}=\frac{\mathrm{D}_{\text {RSS }}}{\omega \mathrm{C}_{\text {RSS }}\left(1+\mathrm{D}_{\text {RSS }}^{2}\right)} \\
& \frac{1}{\omega \mathrm{C}_{\text {Soil }}\left(1+\mathrm{D}_{\text {Soil }}^{2}\right)}+\frac{1}{\omega \mathrm{C}_{\text {Root }}\left(1+\mathrm{D}_{\text {Root }}^{2}\right)}=\frac{1}{\omega \mathrm{C}_{\mathrm{RSS}}\left(1+\mathrm{D}_{\text {RSS }}^{2}\right)}
\end{aligned}
$$

As $C_{\text {Soil }}, D_{\text {Soil }}, C_{R S S}$ and $D_{R S S}$ were measured instrumentally in the experiment, $C_{R o o t}$ and $D_{\text {Root }}$ may be determined by first transforming Eq. (7) and (8) into Eq. (9) and (10), respectively (to express the real and imaginary parts for the root circuit), and then calculating $D_{\text {Root }}$ by dividing Eq. (9) by Eq. (10), obtaining Eq. (11):

$$
\begin{aligned}
& \frac{\mathrm{D}_{\text {Root }}}{\omega \mathrm{C}_{\text {Root }}\left(1+\mathrm{D}_{\text {Root }}^{2}\right)}=\frac{\mathrm{D}_{\text {RSS }}}{\omega \mathrm{C}_{\text {RSS }}\left(1+\mathrm{D}_{\text {RSS }}^{2}\right)}-\frac{\mathrm{D}_{\text {Soil }}}{\omega \mathrm{C}_{\text {Soil }}\left(1+\mathrm{D}_{\text {Soil }}^{2}\right)} \\
& \frac{1}{\omega \mathrm{C}_{\text {Root }}\left(1+\mathrm{D}_{\text {Root }}^{2}\right)}=\frac{1}{\omega \mathrm{C}_{\text {RSS }}\left(1+\mathrm{D}_{\text {RSS }}^{2}\right)}-\frac{1}{\omega \mathrm{C}_{\text {Soil }}\left(1+\mathrm{D}_{\text {Soil }}^{2}\right)} \\
& \mathrm{D}_{\text {Root }}=\frac{\mathrm{D}_{\text {RSS }} \mathrm{C}_{\text {Soil }}\left(1+\mathrm{D}_{\text {Soil }}^{2}\right)-\mathrm{D}_{\text {Soil }} \mathrm{C}_{\text {RSS }}\left(1+\mathrm{D}_{\text {RSS }}^{2}\right)}{\mathrm{C}_{\text {Soil }}\left(1+\mathrm{D}_{\text {Soil }}^{2}\right)-\mathrm{C}_{\text {RSS }}\left(1+\mathrm{D}_{\text {RSS }}^{2}\right)}
\end{aligned}
$$

Then $\mathrm{C}_{\mathrm{Root}}$ can be calculated as (Eq. 12):

$$
\mathrm{C}_{\text {Root }}=\frac{\frac{1}{1+\mathrm{D}_{\text {Root }}^{2}}}{\frac{1}{\mathrm{C}_{\text {RSS }}\left(1+\mathrm{D}_{\mathrm{RSS}}^{2}\right)}-\frac{1}{\mathrm{C}_{\text {Soil }}\left(1+\mathrm{D}_{\text {Soil }}^{2}\right)}}
$$

